\title{
Renal histology and immunohistochemistry after acute hemorrhage in rats under sevoflurane and ketoprofen effect ${ }^{1}$
}

\author{
Histologia e imuno-histoquímica renais após hemorragia aguda em ratos sob efeito do \\ sevoflurano e cetoprofeno
}

\begin{abstract}
Francisco Sobreira Guedes Jr', Deyvid Santos da Cruz ${ }^{\mathrm{II}}$, Marcela Marcondes Pinto Rodrigues ${ }^{\mathrm{III}}$, Leopoldo Muniz da Silva ${ }^{\mathrm{IV}}$, Renée Laufer Amorimv, Pedro Thadeu Galvão Vianna ${ }^{\text {VI, Yara Marcondes Machado Castiglia }}{ }^{\mathrm{VII}}$

${ }^{\mathrm{I}}$ Fellow MSc degree, Postgraduate Program in Anesthesiology, UNESP, Brazil. Main author: responsible for conception, design, intellectual and scientific content of the study.

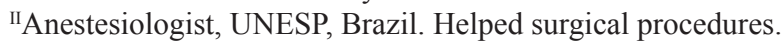

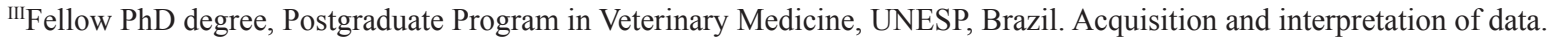

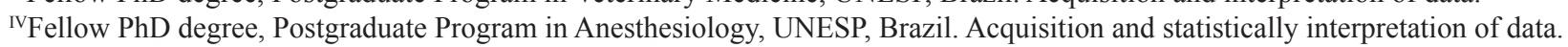

vAssistant Professor, Veterinary Medicine and Zootecny, UNESP, Brazil. Critical revision.

${ }^{\mathrm{VI}}$ Full Professor, Department of Anesthesiology, UNESP, Brazil. Critical revision.

${ }^{V I I} F u l l$ Professor, Department of Anesthesiology, UNESP, Brazil. Tutor: supervised all phases of the study and manuscript writing.
\end{abstract}

\begin{abstract}
PURPOSE: To investigate the influence of intravenous nonselective cyclooxygenase inhibitor, ketoprofen (keto), on kidney histological changes and kidney cytokines, tumor necrosis factor- $\alpha$ (TNF- $\alpha$ ) and interleukin-1 (IL-1), levels after hemorrhage of $30 \%$ of volemia (three times $10 \%$, intervals of $10 \mathrm{~min}$ ) in rats.

METHODS: Under sevoflurane (sevo) anesthesia, sevo and sevo+keto groups (10 rats each) were instrumented for Ringer solution $(5 \mathrm{~mL} / \mathrm{kg} / \mathrm{h})$ administration and mean arterial pressure (MAP) evaluation, plus keto $(1.5 \mathrm{mg} / \mathrm{kg})$ administration in sevo+keto group in the beginning of anesthesia. Rectal temperature was continuously measured. The baseline data of temperature and MAP were collected at the first hemorrhage (T1), the third hemorrhage (T2) and 30min after T2 (T3). Bilateral nephrectomy was achieved for histology and immunohistochemistry.

RESULTS: In both groups, temperature and MAP diminished from initial values. Hypothermia was greater in sevo group ( $\mathrm{p}=0.0002$ ). Tubular necrosis was more frequent in sevo group $(\mathrm{p}=0.02)$. The studied cytokines were equally present in the kidneys of both groups. CONCLUSION: Ketoprofen was more protective to the rat kidney in condition of anesthesia with sevoflurane and hypovolemia, but it seems that TNF- $\alpha$ and IL-1 were not involved in that protection.
\end{abstract}

Key words: Ketoprofen. Hemorrhage. Kidney. Cytokines. Necrosis. Rats.

\section{RESUMO}

OBJETIVO: Investigar a influência do inibidor não-seletivo da ciclooxigenase, cetoprofeno (ceto) intravenoso, em alterações histológicas e dos níveis das citocinas renais - fator $\alpha$ de necrose tumoral (TNF- $\alpha$ ) e interleucina 1 (IL-1) - após hemorragia de 30\% da volemia (10\%, três vezes, em intervalos de $10 \mathrm{~min})$.

MÉTODOS: Sob anestesia com sevoflurano (sevo), os grupos sevo e sevo+ceto (10 ratos cada) foram preparados cirurgicamente para leitura de pressão arterial média (PAM) e administração de solução de Ringer $(5 \mathrm{~mL} / \mathrm{kg} / \mathrm{h})$ e de cetoprofeno $(1,5 \mathrm{mg} / \mathrm{kg})$, no início da anestesia, no grupo sevo+ceto. Mediu-se temperatura retal continuamente. Os valores de temperatura e PAM foram observados antes da primeira hemorragia (T1), após a terceira hemorragia (T2) e 30 min após T2 (T3). Realizada nefrectomia bilateral nos dois grupos para análise histológica e imuno-histoquímica.

RESULTADOS: Nos dois grupos, temperatura e PAM diminuíram com relação aos valores basais. Hipotermia foi mais acentuada no grupo sevo $(\mathrm{p}=0,0002)$. Necrose tubular foi mais frequente no grupo sevo $(\mathrm{p}=0,02)$. As citocinas estiveram igualmente presentes nos rins dos dois grupos.

CONCLUSÃO: Cetoprofeno foi mais protetor no rim de rato durante anestesia com sevoflurano e hipovolemia, porém parece que TNF$\alpha$ e IL-1 não estão envolvidas nessa proteção.

Descritores: Cetoprofeno. Hemorragia. Rim. Citocinas. Necrose. Ratos. 


\section{Introduction}

Hemorrhagic shock is defined as a failure of adequate tissue perfusion resulting from a loss of circulating blood volume. Poor blood supply to the tissues ultimately affects every cell in the body and organ dysfunction will quickly develop if tissue perfusion fails. Maintenance of circulating blood volume is one of the most important homeostatic mechanisms that is mandatory to support. Untreated or inadequately treated hemorrhagic shock will ultimately result in serious consequences for the patient. Limited or inadequate restoration of circulating volume will give rise to profound inflammatory changes. Inflammatory cytokines are liberated within the circulation also during resuscitation and membrane injury occurs in many cells ${ }^{1}$.

During anesthesia for surgery in which is predicted loss of low blood volume, the occurrence of abrupt and significant hemorrhage may restrain the prompt correction of hemorrhage source and recovery of normal circulating blood volume may not be possible either with blood components or colloids/crystalloids. While replacement of blood loss is not achieved, which could be the state of the body organs and systems? The kidneys will be under prostaglandins (hemorrhage) and anesthetics (surgery) effects and, in some cases, also with a preemptive analgesia with a nonsteroidal anti-inflammatory drug (NSAID), such as ketoprofen. As NSAIDs also have analgesic, antipyretic, and nonselective cyclooxygenase (COX) inhibition properties ${ }^{2}$, the conditions of the kidneys concerning inflammation and histological injuries under these compounds are unknown.

Because these issues were not yet clarified, researches are required to study kidney response when the organ has an ischemic/ hypotensive injury under the action of inhalational anesthetic, that may be protective ${ }^{3}$ or not $^{4}$, and of a NSAID, presupposed as an aggressive agent, but showing promising results in some situations ${ }^{5}$.

The aim of this study was to evaluate changes produced by acute hemorrhage, not followed by adequate volume resuscitation, in renal histology and immunohistochemistry of rats under the action of sevoflurane and ketoprofen.

\section{Methods}

This study was performed in accordance with the guidelines of the Ethics Committee in Animal Experimentation of the Botucatu Medical School, UNESP. Twenty adult Wistar rats were randomly divided into two groups of 10 rats each: sevo+keto group and sevo group; all rats were anesthetized with sevoflurane and subjected to $30 \%$ blood volume loss. The rats in the group sevo+keto received ketoprofen intravenously. The animals were housed in a transparent bell made of inert material and injected with $4 \%$ sevoflurane with a total flow of $1 \mathrm{~L} / \mathrm{min}$ of $\mathrm{O}_{2}$ and $1 \mathrm{~L} / \mathrm{min}$ of air from an Ohmeda vaporizer (USA). After the induction, the anesthetic concentration was decreased to $2.5 \%$ and an appropriate non-rebreathing mask system was used; the rats maintained spontaneous breathing in the oxygen/air/sevoflurane mixture. The rectal temperature was monitored and maintained between $35.5^{\circ} \mathrm{C}$ and $37.5^{\circ} \mathrm{C}$ with a compressor-heater system.

The right internal jugular vein was dissected and cannulated with a $24 \mathrm{GA}$ venocath; rats received $5 \mathrm{~mL} / \mathrm{kg} / \mathrm{h}$ of a lactated Ringer solution for replacement of negligible losses using an Anne ${ }^{\circledR}$ infusion pump (Abbott, USA) ${ }^{5,6}$. Immediately after, group sevo+keto received ketoprofen, $1.5 \mathrm{mg} / \mathrm{kg}$. The left carotid artery was dissected and cannulated with a $24 \mathrm{GA}$ venocath to monitor the mean arterial pressure (MAP) using the Datex Engstron recording device (Finland). Sixty minutes after ketoprofen administration in the group sevo+keto and the corresponding time in the group sevo, the animals from the two groups underwent $30 \%$ blood volume loss through the carotid artery, which was performed three times every ten minutes. At each hemorrhage time point, $10 \%$ of the total blood volume was withdrawn, total blood volume been calculated as $6 \%$ of the body weight ${ }^{7}$.

After the last hemorrhage, the rats remained anesthetized for another 30 minutes, a bilateral nephrectomy was conducted, both kidneys were removed and immediately sectioned along the longest axis, and the animals were euthanized with potassium chloride, 19.1\%. The kidneys were stored in separate vials for immunohistochemical and histological analysis in a DuboscqBrazil solution $(120 \mathrm{~mL}$ formaldehyde, $30 \mathrm{~mL}$ acetic acid and $2 \mathrm{~g}$ picric acid), for a minimum of 12 hours and a maximum of 36 hours; they were then transferred to a solution of $70 \%$ ethanol. Finally, coded numbers identified the kidneys. Slices with fragments from both kidneys were prepared by fixing in paraffin and then staining with hematoxylin/eosin. Histology was evaluated and based on the following criteria: vascular ectasia, vascular congestion, tubular dilation, tubular degeneration, necrosis, and inflammatory cells. Tubular necrosis was diagnosed by identifying nuclear necrosis and cytoplasmatic debris. Findings were attributed scores corresponding to the injury importance level: zero (0) absence of injury, one (1) mild injuries, two (2) moderate injuries, and three (3) intense injuries.

For the immunohistochemistry reactions, $4 \mu \mathrm{m}$-thick sections from paraffin embedded material were collected on a histological slide previously treated with (3-Aminopropyl) 
triethoxysilane (Sigma A 3648). The sections were deparaffinized in 2 xylene washes of 30 and 20 minutes, respectively, at room temperature, dehydrated in alcohol for 5 minutes, and then washed with distilled water. Next, the sections were subjected to antigen retrieval in a $96^{\circ} \mathrm{C}$ water bath with pre-heated TRIS EDTA pH 9.0 solution for 30 minutes. After this period, the sections were washed in distilled water and then treated with hydrogen peroxide $\left(\mathrm{H}_{2} \mathrm{O}_{2}\right)$ for 20 minutes to block endogenous peroxidase. The sections were washed in distilled water in two TRIS $\mathrm{pH} 7.5$ washes for 5 minutes and incubated with normal rabbit serum for 20 minutes at room temperature. Next, the sections were incubated with antigenspecific primary goat anti-rat TNF- $\alpha$ (R\&D Systems AF 510-NA) and goat anti-rat IL-1 antibodies (R\&D Systems AF 501-NA), diluted 1:100 in diluent specific for the antibodies with background reduction (DAKO Cytomation $-\mathrm{S} 3022$ ) for 18 hours at $4^{\circ} \mathrm{C}$. The slides were washed in buffer solution, two washes for five minutes each. After this period, they were incubated with secondary biotinylated rabbit anti-goat antibody (Southern Biotech 6160-08), diluted 1:200 for 30 minutes at room temperature in humidified chambers, and washed in two washes of TRIS pH 7.4 for five minutes. The slides were incubated with complex streptoavidin peroxidase (Dako Cytomation K 0377), diluted 1:200 at room temperature for 30 minutes in a humidified chamber and washed in TRIS (two washes) for five minutes. For reaction visualization, the sections were treated with DAB chromogen (DAB Dako Cytomation K 3468) for five minutes and were then washed in TRIS and distilled water. The sections were counterstained with Harris hematoxylin for three minutes, washed in water for ten minutes with subsequent alcohol dehydration, cleared in xylene, and mounted on slides with Permount synthetic resin. The analysis was conducted on all the sections at a magnification of $20 \mathrm{X}$ and $40 \mathrm{X}$, establishing an average for the stain intensity observed on the kidney slides of all the animals: up to $25 \%$ of the field, 26 to $50 \%$ of the field, 51 to $75 \%$ of the field, and 76 to $100 \%$ of the field. For the negative control group, the primary antibodies were omitted. Positive signal was detected as brown staining with a cytoplasmic and cellular membrane pattern.

The studied attributes were as follows: rat weight, rectal temperature, mean arterial pressure, histological analysis of the kidney, tumor necrosis factor-alpha (TNF- $\alpha)$ and interleukin-1 (IL-1) cytokines immunostaining in the kidney. The temperature and mean arterial pressure were studied in time points T1, coincident with the first hemorrhage, $\mathrm{T} 2$, coincident with the third hemorrhage, and T3, which occurred 30 minutes from the third and last hemorrhage and immediately before the euthanasia of each animal.

\section{Statistical analysis}

The Friedman test was used to compare body weight between groups, as well as rectal temperature and mean arterial pressure values between groups at the same time point. The Mann-Whitney test was used to compare the results of intensity of cytokine staining and histological analysis in the kidney between groups and the Wilcoxon test to compare right and left kidneys results inside a group. Significance level was set at $\mathrm{p}<0.05$.

\section{Results}

The animal weights $(\mathrm{g})$ did not differ between sevo+keto group and sevo group, and were, respectively, $459 \pm 40$ and $421 \pm 105$. For sevo+keto group, the rectal temperatures $\left({ }^{\circ} \mathrm{C}\right)$ were $37.1 \pm 1.0(\mathrm{~T} 1), 37.9 \pm 1.1(\mathrm{~T} 2)$ and $37.5 \pm 1.0(\mathrm{~T} 3)$, while for sevo group, the rectal temperatures were $35.7 \pm 0.9$ (T1), $35.7 \pm 1.0$ (T2) and $35.7 \pm 0.7(\mathrm{~T} 3)$. There were significant differences between the two groups with respect to moments $(\mathrm{p}<0.003,0.0002$, and 0.0002 , respectively) (Figure 1). There was a significant decrease in the mean arterial pressure $(\mathrm{mmHg})$ for both groups, respectively for sevo+keto and sevo groups: $95.7 \pm 12.1$ (T1), $50.6 \pm 20.9$ (T2), and $58.8 \pm 18.7(\mathrm{~T} 3)(\mathrm{p}<0.001)$ and $99.0 \pm 15.0(\mathrm{~T} 1), 55.4 \pm 21.0$ (T2), and $67.3 \pm 22.7(\mathrm{~T} 3)(\mathrm{p}<0.002)$ (Figure 2).

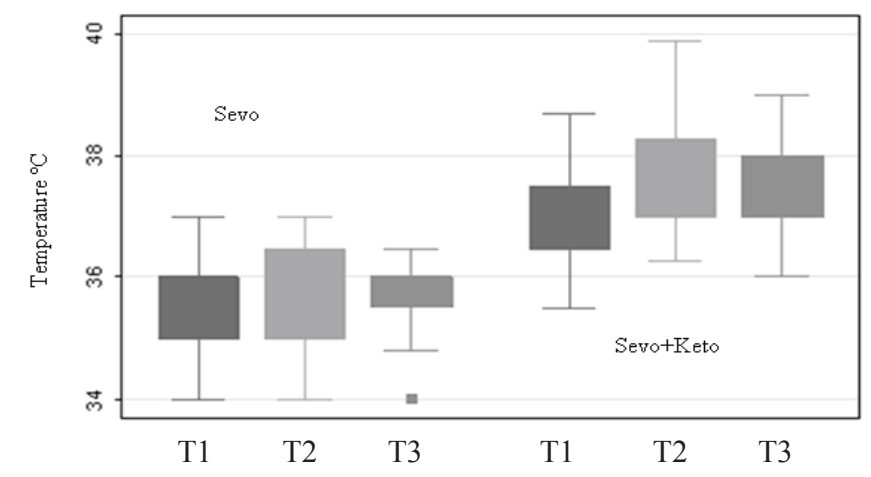

FIGURE 1 - Box-plot. Temperature mean and standard deviation values $\left({ }^{\circ} \mathrm{C}\right)$ of the rats of the sevoflurane + ketoprofen (sevo+keto) and sevoflurane (sevo) groups in the three time points studied T1, coincident with the first hemorrhage, T2, coincident with the third hemorrhage, and T3, 30 min after T2 ( $\mathrm{p}=0.003,0.0002,0.0002$ in T1, T2 and T3, respectively). 


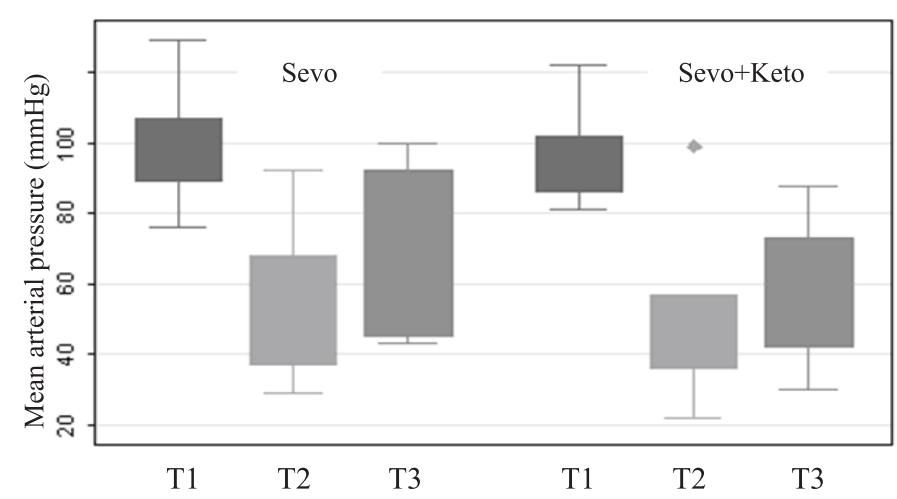

FIGURE 2 - Box-plot. Mean of the mean arterial pressure and standard deviation values $(\mathrm{mmHg})$ of the rats of the sevoflurane+ketoprofen (sevo+keto) and sevoflurane (sevo) groups in the three time points studied, T1, coincident with the first hemorrhage, T2, coincident with the third hemorrhage, and T3, 30 min after T2 ( $<<0.001$ for sevo+keto group decrease, and $\mathrm{p}<0.002$ for sevo group decrease).

Table 1 shows median, $25^{\text {th }}$ and $75^{\text {th }}$ percentiles of the change intensity scores and significances of the studied variables in the histological analysis: vascular ectasy, vascular congestion, tubular dilation, tubular degeneration, tubular necrosis and presence of inflammatory cells. Left kidneys of sevo+keto group had significantly more vascular ectasy than left kidneys of sevo group, and right kidneys of sevo group had significantly more tubular necrosis than right kidneys of sevo+keto group (Figure 3 ). With respect to renal expression of the TNF- $\alpha$ and IL- 1 of the two groups, Table 2 shows median, $25^{\text {th }}$ and $75^{\text {th }}$ percentiles of the change intensity scores and significances. There was expression of the two cytokines in the kidneys of all studied animals but there was not difference between groups (Figure 3).
TABLE 1 - Scores of histological analysis (HA): vascular ectasy (VE), vascular congestion (VC), tubular dilation (TD), tubular degeneration (TDg), tubular necrosis (TN), inflammatory cells (IC) (data reported as median, $25^{\text {th }}$ and $75^{\text {th }}$ percentile) in the right $(\mathrm{R})$ and left $(\mathrm{L})$ kidneys according to group, sevo+keto or sevo.

\begin{tabular}{ccccccc}
\hline Groups & \multicolumn{3}{c}{ Sevo+Keto } & \multicolumn{3}{c}{ Sevo } \\
\hline HA & $\mathbf{R}$ & $\mathbf{L}$ & $\mathbf{p}$ & $\mathbf{R}$ & $\mathbf{L}$ & $\mathbf{p}$ \\
$\mathbf{V E}$ & $1(1 ; 1)$ & $2(1 ; 2)$ & $* 1.00 ; \# 0.22$ & $1(1 ; 1)$ & $1(1 ; 2)$ & $\mathrm{Rp}=0.17 ; \mathrm{Lp}=0.01$ \\
$\mathbf{V C}$ & $0(0 ; 0.75)$ & $0.5(0 ; 1)$ & $* 1.00 ; \# 0.10$ & $0(0 ; 0.75)$ & $0(0 ; 0.75)$ & $\mathrm{Rp}=0.42 ; \mathrm{Lp}=1.00$ \\
TD & $1(1 ; 1)$ & $2(1 ; 2)$ & $* 0.17 ; \# 0.50$ & $1(1 ; 2)$ & $2(1 ; 2)$ & $\mathrm{Rp}=0.13 ; \mathrm{Lp}=0.65$ \\
TDg & $1(0.25 ; 1)$ & $1(1 ; 1)$ & $* 0.59 ; \# 0.59$ & $1(0 ; 1)$ & $1(1 ; 1)$ & $\mathrm{Rp}=0.09 ; \mathrm{Lp}=0.11$ \\
TN & $0.5(0 ; 1)$ & $1(1 ; 1)$ & $* 0.06 ; \# 0.17$ & $1(0 ; 1)$ & $1(1 ; 1)$ & $\mathrm{Rp}=0.02 ; \mathrm{Lp}=0.70$ \\
IC & $0(0 ; 0)$ & $0.5(0 ; 1.75)$ & $* 0.06 ; \# 0.59$ & $0(0 ; 0)$ & $0(0 ; 0)$ & $\mathrm{Rp}=0.44 ; \mathrm{Lp}=0.17$ \\
\hline
\end{tabular}

Intensity of injuries: zero (0) absence of injury, one (1) mild injuries, two (2) moderate injuries, and three (3) intense injuries; *p compares right and left kidneys inside sevo+keto group; \#p compares right and left kidneys inside sevo; Rp and Lp compare right and left kidneys between groups; ( $p$ significantly different when $<0.05$ ).

TABLE 2 - Scores of IL-1 and TNF- $\alpha$ (data reported as median, $25^{\text {th }}$ and $75^{\text {th }}$ percentile) in the $\operatorname{right}(\mathrm{R})$ and left $(\mathrm{L})$ kidney according to group, sevoflurane+ketoprofen (sevo+keto) or sevoflurane (sevo).

\begin{tabular}{ccccccc}
\hline Groups & \multicolumn{3}{c}{ Sevo+Keto } & \multicolumn{3}{c}{ Sevo } \\
\hline Cytokines & $\mathbf{R}$ & $\mathbf{L}$ & $\mathbf{p}$ & $\mathbf{R}$ & $\mathbf{L}$ & $\mathbf{p}$ \\
\hline IL-1 & $3(3 ; 3)$ & $3(3 ; 3)$ & $\begin{array}{c}* 1.00 ; \\
\# 1.00\end{array}$ & $2(2 ; 3)$ & $2(2 ; 3)$ & $\begin{array}{c}\mathrm{Rp}=0.11 \\
\mathrm{Lp}=0.11\end{array}$ \\
TNF- $\boldsymbol{\alpha}$ & $3(2.25 ; 3)$ & $2.5(2 ; 3)$ & $\begin{array}{c}* 0.36 ; \\
\# 0.37\end{array}$ & $3(2 ; 3)$ & $2(2 ; 3)$ & $\begin{array}{c}\mathrm{Rp}=0.62 ; \\
\mathrm{Lp}=0.57\end{array}$ \\
\hline
\end{tabular}

Intensity of injuries: zero (0) absence of injury, one (1) mild injuries, two (2) moderate injuries, and three (3) intense injuries; ${ }^{*}$ p compares right and left kidneys inside sevo+keto group; \# compares right and left kidneys inside sevo group; Rp and Lp compare right and left kidneys between groups; ( $p$ significantly different when $<0.05$ ). 


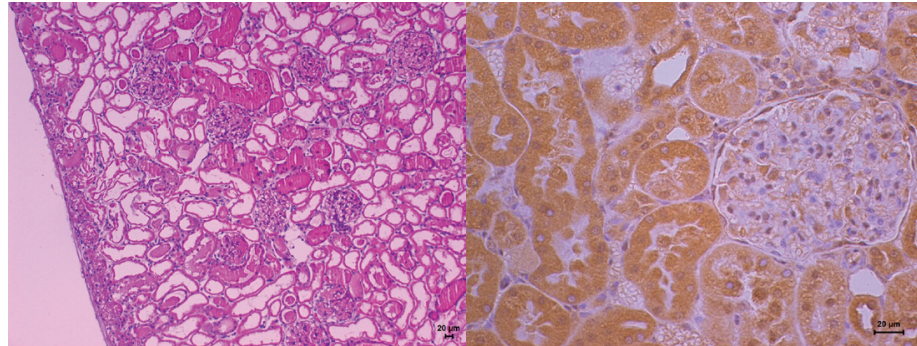

FIGURE 3 - Hematoxylin \& eosin-stained histological sections (left) and immunohistochemistry - interleukin-1 (right) of rat kidneys after hemorrhage of $30 \%$ of volemia, under sevoflurane anesthesia (sevo group) plus ketoprofen (sevo+keto group) (left) Renal tubular dilation and necrosis. 10x. HE, bar $=20 \mu \mathrm{m}$. (right): intense $(3+)$ renal tubular expression of interleukin-1. Bar $=20 \mu \mathrm{m}$. Immunohistochemistry, IL-1, ABC, DAB, contra-coloration Harris hematoxylin.

\section{Discussion}

In this study, the clinical situation of routine anesthesia for surgery with acute nonexpected hemorrhage, not followed by prompt blood volume resuscitation, combined to the use of preemptive analgesia with a NSAID, a potential prostaglandin inhibitor, was intentionally mimicked. In this situation, during anesthesia, the vasoconstriction that follows hemorrhage will cause damage to the kidneys.

The rectal temperature reported in this study was lower in the sevo group and the mild hypothermia observed would be protective to the organ, significantly minimizing the kidney injury severity ${ }^{8}$. However, in this group necrosis was significantly higher than in sevo+keto group, what suggests some protective effect of ketoprofen. Administration of supportive fluids to lessen hypotension was intentionally withheld in this study in order to mimic possible clinical situations

According to the classification of hemorrhage ${ }^{1}$, our rats are in class III, the condition when shock is well established and a critical phase is reached, with a drop in systolic and diastolic blood pressure, as seen in this study. The increase in MAP at the end of the experiment may reflect a physiologic response to hemorrhage and decreased circulating volume.

Although the severity of hemorrhage is related to the percentage of total blood volume lost, the duration of the shock is also of significant importance ${ }^{9}$. Resuscitation should begin as early as possible; so, hypoperfusion in intervals greater than six to 12 hours likely cannot be reversed completely with subsequent hemodynamic optimization ${ }^{10}$. As a decrease in circulating blood volume provokes homeostatic response to maintain blood flow to the brain and heart, other organs, like the kidneys, can be damaged.

It is known that low perfusion conditions, as is the case of hemorrhagic shock, produce widespread cellular hypoxia, triggering systemic inflammation ${ }^{1}$. Depending on the degree of the hypotensive insult, the kidney may manifest acute spasm of the preglomerular arterioles that leads to acute tubular necrosis. In our study, necrosis occurred in both groups, but was more intense in sevo group, even with the mild hypothermia seen in these animals, known to be protective to the kidneys. These findings may suggest a protective role of ketoprofen against renal aggression.

Immune response following hemorrhagic shock is characterized by an early proinflammatory cytokine release such as interleukin (IL)-6, IL-1, or TNF- $\alpha$, which appears immediately after the injury ${ }^{11}$. The kidney is an endocrine organ that regulates and produces many substances, such as cytokines, and so, is capable of producing TNF- $\alpha$ in response to multiple trauma and ischemia/reperfusion injuries, and also through its own TNF- $\alpha$ up-regulation mechanism or through its own IL-1 released. Biologically IL-1 and TNF- $\alpha$ are closely related, although their structures and receptors are distincts ${ }^{12}$. These cytokines can modulate renal hemodynamics and probably mediate clinical and laboratory manifestations of some renal diseases ${ }^{13}$. In this study, the presence of cytokines TNF- $\alpha$ and IL-1 were significantly high after hemorrhage, but without differentiation between groups.

When hypovolemia occurs, norepinephrine, angiotensine II, and antidiuretic hormone act to maintain blood pressure and preserve perfusion in important vascular beds. These substances stimulate vasoconstriction in relatively less important vascular beds, such as splanchnic circulations ${ }^{14}$. Acute tubular necrosis (ATN) is part of a spectrum of manifestations of renal hypoperfusion, being the result of severe and prolonged hypoperfusion ${ }^{15}$. In our study both groups presented tubular necrosis, but sevo+keto group showed lower scores. Knowing that hypothermia protects from ischemic injuries, this lighter degree of necrosis of sevo group might be due to the hypothermia presented by these animals, which was more important than that of the sevo+keto group. In this way, ketoprofen may have protected the kidneys against the hypoperfusion.

Further experiments will be necessary to elucidate the involvement of ketoprofen in the histological changes of rat kidney after acute hemorrhage.

\section{Conclusion}

Ketoprofen exhibited a protective effect on rat kidney in situation of anesthesia with sevoflurane and hypovolemia after acute hemorrhage, although it seems that TNF- $\alpha$ and IL-1 are not involved in this protection. 


\section{References}

1. Garrioch MA. The body's response to blood loss. Vox Sang. 2004;87(Suppl 1):574-6.

2. Nathan C. Points of control in inflammation. Nature. 2002;420(6917):846-52.

3. Zaugg M, Lucchinetti E, Spahn DR, Pasch T, Schaub MC. Volatile anesthetics mimic cardiac preconditioning by priming the activation of mitochondrial K(ATP) channels via multiple signaling pathways. Anesthesiology. 2002;97:4-14.

4. Obal D, Dettwiler S, Favoccia C Rascher K, Preckel B, Schlack W. Effect of sevoflurane preconditioning on ischemia/reperfusion injury in the rat kidney in vivo. Eur J Anaesthesiol. 2006;23:319-26.

5. de Souza Silva M, Castiglia YM, Vianna PT, Viero RM, Braz JR, Cassetari ML. Rat model of depending prostaglandin renal state: effect of ketoprofen. Ren Fail. 2006;28(1):77-84.

6. Diego LAS, Marques CD, Vianna PT, Viero RM, Braz JR, Castiglia YM. Glibenclamide effects on renal function and histology after acute hemorrhage in rats under sevoflurane anesthesia. Ren Fail. 2007;29(8):1029-45.

7. Erni D, Banic A, Wheatley AM, Sigurdssonn GH. Haemorrhage during anaesthesia and surgery: continuous measurement of microcirculatory blood flow in the kidney, liver, skin and skeletal muscle. Eur J Anaesthesiol. 1995;12:423-9.

8. Delbridge MS, Shrestha BM, Raftery AT, El Nahas AM, Haylor JL. The effect of body temperature in a rat model of renal ischemia/ reperfusion injury. Transplant Proc. 2007;39:2983-5.

9. Lomas-Niera JL, Perl M, Chung CS, Ayala A. Shock and hemorrhage: an overview of animal models. Shock. 2005;24:33-9.

10. Pieracci FM, Biffl WL, Moore EE. Current Concepts in Resuscitation. $\mathrm{J}$ Intensive Care Med 2011. [Epub ahead of print].

11. Oberholzer A, Oberholzer C, Moldawer LL. Cytokine signalingregulation of the immune response in normal and critically ill states. Crit Care Med. 2000;28(4 Suppl):N3-12.

12. Dinarello CA. Proinflammatory and anti-inflammatory cytokines as mediators in the pathogenesis of septic shock. Chest. 1997;112:321S9S.

13. Balat A. Kidney is in trouble with mediators. Bosn J Basic Med Sci. 2010;10 Suppl 1:S29-36.

14. Thadhani R, Pascual M, Bonventre JV. Acute renal failure. N Engl J Med. 1996;334:1448-60.

15. Mehta RL, Pascual MT, Soroko S, Savage BR, Himmelfarb J, Ikizler TA, Paganini EP, Chertow GM; Program to Improve Care in Acute Renal Disease. Spectrum of acute renal failure in the intensive care unit: the PICARD experience. Kidney Int. 2004;66:1613-21

\section{Correspondence:}

Yara Marcondes Machado Castiglia

Faculdade de Medicina Botucatu-UNESP

Depto. Anestesia

Rubião Júnior, s/n

Caixa Postal 530

18618-970 Botucatu - SP Brasil

Tel./Fax: (55 14)3811-6222

yarac@fmb.unesp.br

Received: August 24, 2011

Review: October 25, 2011

Accepted: November 21, 2011

Conflict of interest: none

Financial source: none

${ }^{1}$ Research performed at Experimental Laboratory of Anesthesiology, Botucatu School of Medicine, Sao Paulo State University (UNESP), Brazil. 